\title{
DRYING OF CITRUS GRANDIS (POMELO) FRUIT JUICE USING BLOCK FREEZE CONCENTRATION AND SPRAY DRYING
}

\author{
D. Das, D. DAs, A.K. GuPtA and P. Mishra* \\ Department of Food Engineering and Technology, Tezpur University, Assam 784028. India
}

(Received: 3 February 2020; accepted: 15 March 2020)

\begin{abstract}
Pomelo fruit juice is concentrated using two different techniques, i.e. block freeze concentration (BFC) and thermal concentration (TC), and both concentrates were spray dried separately to observe the effects of two different concentration techniques on the physicochemical properties of the spray dried powder. BFC juice had comparatively better values of retention of acidity, colour, vitamin C, DPPH• scavenging activity, total phenolic content (TPC), and total sugar content than TC juice. The powder obtained from the combination of BFC and spray drying had better retention of vitamin C (121.17 mg/100 g), colour, and exhibited higher DPPH• scavenging activity than TC spray dried powder. The physical parameters including solubility index, bulk density, and hygroscopicity were significantly higher in BFC spray dried powder. BFC was observed as an efficient concentration technique in comparison to TC as a pretreatment to produce spray dried powder with a better retention of bioactive components and powder flow properties.
\end{abstract}

Keywords: pomelo juice powder, block freeze concentration, thermal concentration, spray drying

Pomelo (Citrus grandis Linn.), a monoembryonic species of the genus Citrus, contains a plethora with nutrients (BHARALI \& SAIKIA, 2004). Beside nutraceutical ingredients such as carotenoids, lycopene, anthocyanin, limonoids, naringin, and water-soluble vitamins, the fruit is also rich in crude fibre and dietary fibre (BOHRA \& SRINIVAS, 2015). Being seasonal in nature, availability of the fruit is limited up to 3-4 months in a year. Production of fruit juice powder is a dehydration technique, which eases storage, transportation, and increases the shelf life up to several months.

Spray drying produces regular and spherical shaped powder particles through the atomisation of fine liquid droplets (FAZAELI et al., 2012). Spray drying of pomelo fruit juice may be a good alternative to make it available throughout the season. The feedstock used for spray drying is usually a pre-concentrate up to $25-30 \%$ for lab-scale spray dryer. Application of heat for pre-concentration adversely affects the physicochemical properties of the juice, so a comparatively inferior quality fruit powder is produced (MURUGESAN \& ORSAT, 2011). Thermal concentration of juice is generally performed by the application of heat energy in batches or in a continuous process (ADNAN et al., 2018). Block freeze concentration (BFC) is a technique where free water can be removed from the feed solution in the form of ice (Petzold et al., 2015). In this technique, the liquid sample is frozen until the temperature at the centre of the product reaches below the freezing point of the sample, and then the free water from the sample is removed through partial thawing and centrifugation.

\footnotetext{
* To whom correspondence should be addressed. Phones: +91 03712 267007,+9103712 267007 (5705); fax: +9103712 267005,267006; e-mails: mpoonam1@ rediffmail.com; poonam@tezu.ernet.in
} 
The present study is undertaken to elucidate the effect of two different pre-concentration techniques (BFC and thermal concentration (TC)) on the physicochemical and antioxidant properties of spray dried pomelo juice powder. As per the best of our knowledge, we are reporting the effect of combination of two different concentration techniques and spray drying on the physicochemical and phytochemical properties of the powder the first time.

\section{Materials and methods}

\subsection{Sample preparation}

Pomelo fruit (collected from campus of Tezpur University, India) juice was extracted from peeled fruit using lab scale juicer (Philips HR 1863/20, India) and was filtered by 3-layered cheesecloth. The extracted juice was stored at $5{ }^{\circ} \mathrm{C}$ for further analysis.

\subsection{Chemical analysis of pomelo juice}

Moisture content, titratable acidity, $\mathrm{pH}$, total soluble solids (TSS), and vitamin C content were calculated as per the method of AOAC (1990) official methods such as AOAC 930.15; AOAC, 942.15; AOAC 981.12; AOAC, 932.14, and AOAC 967.21, respectively. Naringin and total phenolic content was determined according to the method given by DAVIS (1947) and MisHra and co-workers (2014), respectively.

\subsection{Overview of experimental method}

Figure 1 illustrates an overall experimental procedure, where pomelo juice was frozen in a deep freezer (Lyolab_3S, Lyophilisation Sytems India Pvt Ltd.) at $-20^{\circ} \mathrm{C}$ and then centrifuged (Eppendorf, Hamburg) to separate the solutes from the solid ice. The fraction received after the first block freeze concentration (BFC) cycle was used as feed solution for the second BFC cycle, and similarly, the second concentrated fraction was used for the third cycle of concentration (PeTzOLD et al., 2015).

\subsection{Freezing time calculation and centrifugation of pomelo juice}

Juice $(25 \mathrm{ml})$ was frozen in static freezer at $-20{ }^{\circ} \mathrm{C}$ (temperature during freezing was calculated using needle type digital thermocouple) for $12 \mathrm{~h}$, and the freezing time of juice was estimated using Planck's equation.

$$
\mathrm{t}_{\mathrm{f}}=\frac{L \rho}{\mathrm{T}_{\mathrm{f}}-\mathrm{T}_{\mathrm{a}}}\left[\frac{P_{\mathrm{a}}}{\mathrm{h}}+\frac{R_{\mathrm{a}^{2}}}{\mathrm{k}_{\mathrm{f}}}\right]
$$

where,

$\mathrm{t}_{\mathrm{f}}=$ freezing time $(\mathrm{h})$

$\mathrm{L}=$ latent heat of fusion of the food $\left(\mathrm{L}=333.2 \mathrm{~kJ} \mathrm{~kg}^{-1}\right)$

$\rho=$ density of the juice (density of juice $1232 \mathrm{~kg} \mathrm{~m}^{-3}$ at $25^{\circ} \mathrm{C}$ )

$\mathrm{P}=$ constant $($ for cylinder $=1 / 4$ )

$\mathrm{R}=$ constant (for cylinder $=1 / 16$ )

$\mathrm{a}=$ thickness of the material $(\mathrm{m})$

$\mathrm{T}_{\mathrm{f}}=$ freezing temperature $\left({ }^{\circ} \mathrm{C}\right)$ (calculated by needle-based thermocouple)

$\mathrm{T}_{\mathrm{a}}=$ freezing temperature of medium $\left({ }^{\circ} \mathrm{C}\right)$ 
$\mathrm{h}=$ convective heat transfer coefficient at the surface of the food $\left(\mathrm{h}=7.26 \mathrm{~W} \mathrm{~m}^{-2} \mathrm{k}^{-1}\right)$

$\mathrm{k}_{\mathrm{f}}=$ thermal conductivity of the frozen food $\left(\mathrm{k}=1.6 \mathrm{~W} \mathrm{~m}^{-2} \mathrm{k}^{-1}\right)$

$\mathrm{L}, \mathrm{h}$, and $\mathrm{K}_{\mathrm{f}}$ value were calculated as per the method of IKEGWU and EKWU (2009). Separation of solutes from the frozen juice was carried out by centrifugation at 5400 rotation centrifugal force (rcf) for $25 \mathrm{~min}$ at $20^{\circ} \mathrm{C}$. After centrifugation, the concentrated juice was collected, and the remaining frozen core was melted to estimate the soluble solids of both fractions.

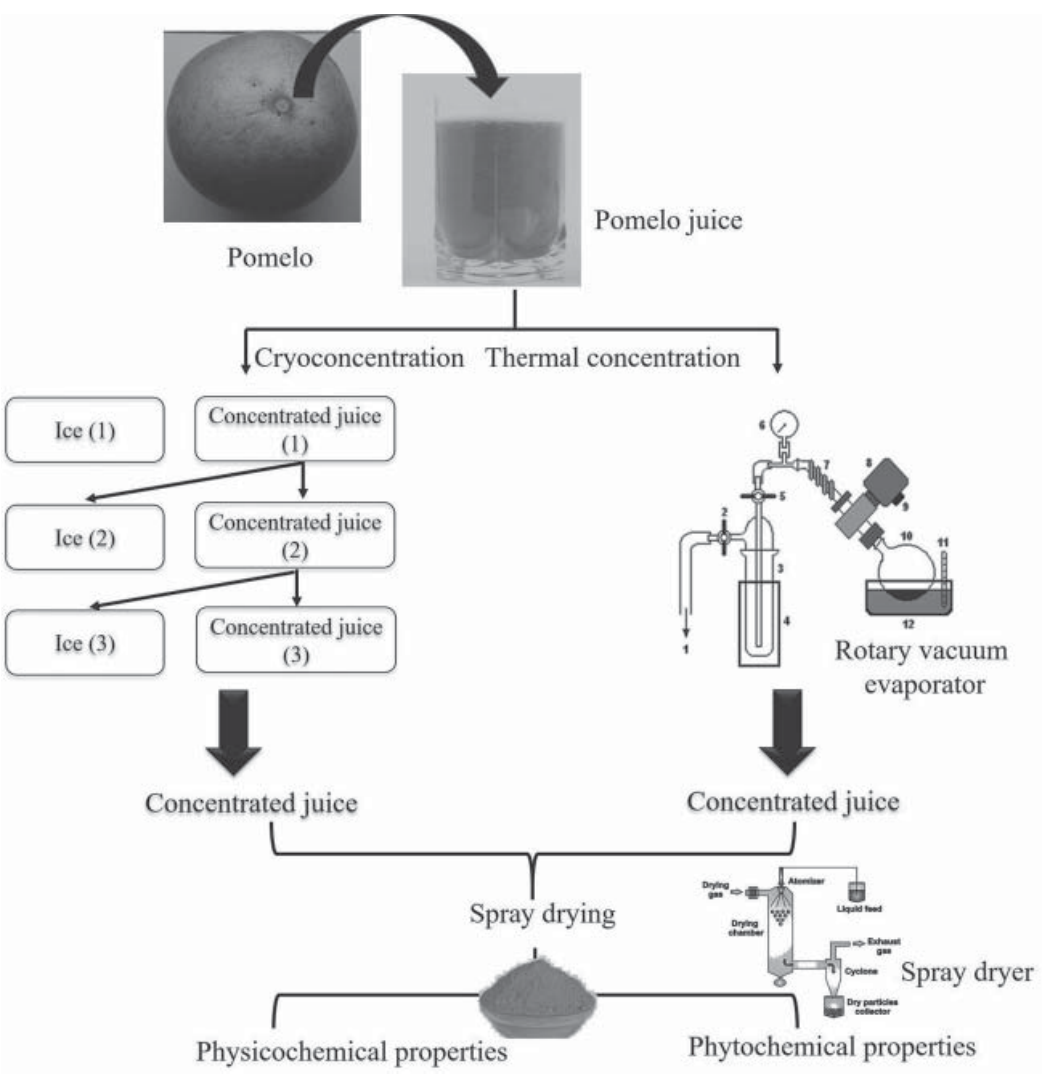

Fig. 1. Generalised scheme of overall experimental procedure

\subsection{Analysis of juice concentrate}

1.5.1. Percentage of concentrate. Percentage of concentrate (\% PC) was estimated for each $\mathrm{BFC}$ using the following equation:

$$
\% \mathrm{PC}=\frac{\mathrm{W}_{\mathrm{i}}-\mathrm{W}_{\mathrm{f}}}{\mathrm{W}_{\mathrm{i}}}
$$

(2) (Petzold et al., 2015)

where, $\mathrm{W}_{\mathrm{i}}$ is initial weight of the frozen fraction and $\mathrm{W}_{\mathrm{f}}$ is the final weight of the frozen fraction. 
1.5.2. Concentration efficiency. Equation 3 was used to calculate the concentration efficiency of the block freeze concentration:

$$
\eta \%=\frac{\mathrm{C}_{\mathrm{s}}-\mathrm{C}_{\mathrm{f}}}{\mathrm{C}_{\mathrm{s}}} \times 100
$$

(3) (Petzold et al., 2015)

where, $\mathrm{C}_{\mathrm{s}}$ and $\mathrm{C}_{\mathrm{f}}$ are the concentrations of soluble solids ( ${ }^{\circ} \mathrm{Brix}$ ) in the juice and frozen fraction, respectively.

1.5.3. Recovery of solute. Recovery of solutes was quantified using the equation 4:

$$
\mathrm{Y}=\frac{\mathrm{C}_{\mathrm{s}} \times \mathrm{M}_{\mathrm{s}}}{\mathrm{C}_{\mathrm{o}} \times \mathrm{M}_{\mathrm{o}}} \quad \text { (4) (PETZOLD et al., 2015) }
$$

where, $\mathrm{Y}=$ recovery of solutes $\left(\mathrm{kg}\right.$ solute $/ \mathrm{kg}$ initial solute), $\mathrm{C}_{\mathrm{o}}$ is the soluble solids $\left({ }^{\circ} \mathrm{Brix}\right)$ present in the initial juice of each $\mathrm{BFC}$ cycle, $\mathrm{M}_{\mathrm{s}}$ and $\mathrm{M}_{\mathrm{o}}$ are mass $(\mathrm{kg})$ of the concentrated juice and initial juice of each cycle respectively.

\subsection{Concentration of juice using thermal concentration (TC)}

Freshly extracted pomelo juice was concentrated in a rotary vacuum evaporator (Equitron, Medica Instruments, India) at a speed of $60 \mathrm{rcf}$ and at $60^{\circ} \mathrm{C}$ till the soluble solids of the juice concentrate became equivalent to the $3^{\text {rd }}$ cycle $\mathrm{BFC}$ juice.

\subsection{Spray drying of concentrated pomelo fruit juice}

The BFC and TC pomelo juice $(250 \mathrm{ml})$ was spray dried in lab scale spray dryer (SD-Basic LabPlant, England) using maltodextrin $(15 \% \mathrm{w} / \mathrm{v}$ of the initial volume of juice). Inlet temperatures and recorded outlet temperatures were $160{ }^{\circ} \mathrm{C}$ and $90{ }^{\circ} \mathrm{C}$, respectively. During spray drying compressor pressure, airflow rate, and feed rate were maintained at $0.12 \mathrm{MPa}$,

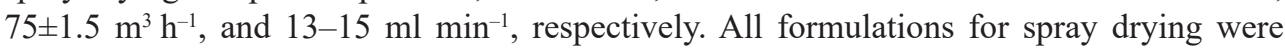
performed in triplicates.

\subsection{Hygroscopicity, water solubility index (WSI), bulk density (BD), DPPH free radical $\left(\mathrm{DPPH}{ }^{\bullet}\right)$ scavenging activity, and colour properties}

Hygroscopicity, WSI, BD, and DPPH $\bullet$ scavenging activity of powders was evaluated as per the method of CAI and CORKE (2000), Subramanian and co-workers (1994), and Mishra and co-workers (2014), respectively. Colour of the spray dried powder was measured using Hunter colour lab (Ultra Scan VIS, USA).

\subsection{Statistical analysis}

All experiments were performed in triplicates, the obtained data were statistically analysed using IBM SPSS Statistics Version 20.0, Armonk, NY: IBM Corporation package, and the data are presented as the mean \pm standard deviation. The means were separated using the Duncan's multiple range test $(\mathrm{P}<0.05)$. 


\section{Results and discussion}

\subsection{Effect of centrifugation time for maximum recovery of solutes}

Juice used for the present investigation had pH 3.64, $8.6^{\circ}$ Brix, $0.98 \%$ acidity, $90 \mathrm{mg} / 100 \mathrm{ml}$ vitamin C, and $90.37 \%$ moisture content. The time for maximum possible recovery of solute during the first cycle of BFC was considered for second and third cycles of BFC (Table 1). The efficiency of concentration progressively increased to $86.95 \%$ in 25 min of centrifugation and thereafter decreased due to loss of solid content. Therefore, $25 \mathrm{~min}$ for centrifugation was considered as the appropriate time for the maximum possible recovery of solute $(0.61 \mathrm{~kg}$ of solute/kg of initial solute).

Table 1. Effect of the time of centrifugation on the efficiency and recovery of solute

\begin{tabular}{llc}
\hline $\begin{array}{l}\text { Centrifugation time } \\
(\mathrm{min})\end{array}$ & Efficiency $(\%)$ & $\begin{array}{c}\text { Recovery of solute } \\
\left(\mathrm{kg} \mathrm{kg}^{-1}\right)\end{array}$ \\
\hline 5 & $67.33 \pm 0.01^{\mathrm{f}}$ & $0.29 \pm 0.03^{\mathrm{f}}$ \\
10 & $73.67 \pm 0.01^{\mathrm{e}}$ & $0.33 \pm 0.01^{\mathrm{e}}$ \\
15 & $78.11 \pm 0.02^{\mathrm{d}}$ & $0.38 \pm 0.01^{\mathrm{d}}$ \\
20 & $82.05 \pm 0.01^{\mathrm{c}}$ & $0.48 \pm 0.02^{\mathrm{c}}$ \\
25 & $86.95 \pm 0.02^{\mathrm{a}}$ & $0.61 \pm 0.01^{\mathrm{b}}$ \\
30 & $83.27 \pm 0.03^{\mathrm{b}}$ & $0.65 \pm 0.01^{\mathrm{a}}$ \\
\hline
\end{tabular}

Values are means \pm standard deviation of three determinations $(n=3)$. Values followed by different superscript letter in a column are significantly different $(\mathrm{P} \leq 0.05)$

\subsection{Calculation of recovery of solute, efficiency, and percentage of concentration}

Figure 2 presents the recovery of the solute after the first BFC cycle, which was $0.61 \mathrm{~kg} \mathrm{~kg}^{-1}$ of the solute of the initial solution, and at the end of third BFC cycle, the recovery of solute reached $0.77 \mathrm{~kg} \mathrm{~kg}^{-1}$ the solute of the initial solution. Due to solid loss in ice, efficiency was reduced from $86.95 \%$ to $83.27 \%$. The $\%$ concentration of juice increased gradually from 22.90 to $39.32 \%$ with the increasing number of cycles of BFC.

\subsection{Effect of concentration on the freezing time of pomelo fruit juice}

The effect of concentration of pomelo juice on freezing time was calculated using Plank's equation. A significant difference between the freezing plateaus of fresh and concentrated juices was clearly noticed (Fig. 3). Raw juice could be frozen in $4.61 \mathrm{~h}$, however, the first cycle, second cycle, and third cycle concentrated juices took 4.90, 5.23, and $5.60 \mathrm{~h}$, respectively. 


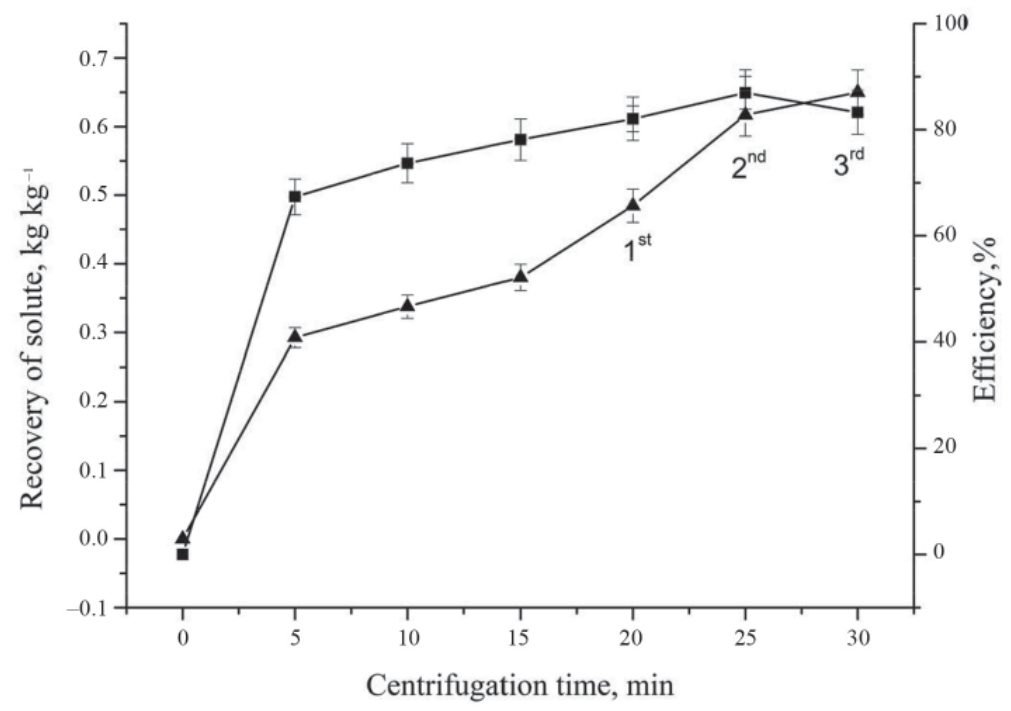

Fig. 2. Percentage efficiency of concentration of solute vs centrifugation time and recovery of solute vs centrifugation time after first BFC cycle

$\longrightarrow$ : Recovery of solutes; $\longrightarrow$ - : efficiency, $\%$

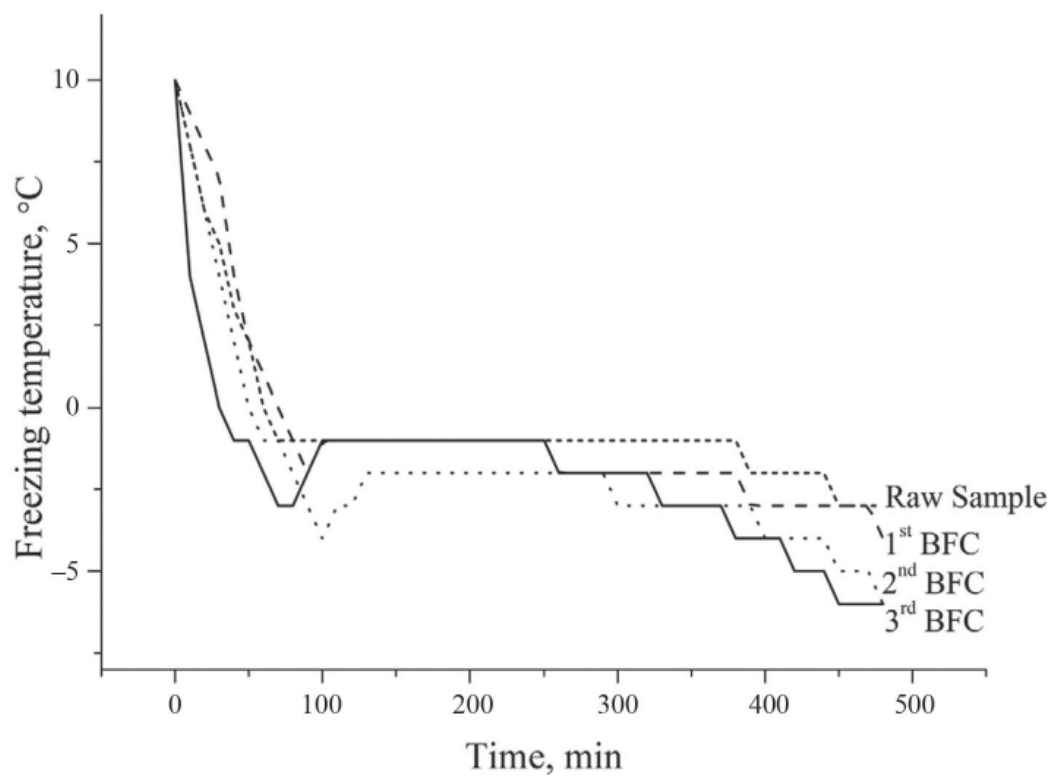

Fig. 3. Freezing curves for raw sample and each BFC cycle 


\subsection{Effect of BFC and TC on chemical and phytochemical properties of pomelo fruit juice}

Moisture content was reduced from $90.37 \%$ to $75.12 \%$ after the third cycle of BFC, while $74.39 \%$ moisture content was recorded in TC juice (Table 2). The TSS increased with the number of cycles and reached 14.7, 17.6, and 22.0\% after first, second, and third BFC cycle, respectively. The final ${ }^{\circ}$ Brix of TC juice was maintained at $22.18^{\circ}$ Brix of concentrated juice. Acidity of BFC juice increased from 0.98 to $1.92 \%$ and acidity of TC juice increased only to $1.27 \%$. An increase in acidity in BFC juice may be due to the concentration-effect only, but on the other hand, heating in TC probably affects the composition of acids and hydrogen ion concentration, so increase in acidity was comparatively lower than in BFC juice.

Being unstable in nature, vitamin $\mathrm{C}$ gets easily destroyed when exposed to heat during concentration (SEMENOv et al., 2015), and TC juice had $36.15 \mathrm{mg} / 100 \mathrm{~g}$ of vitamin C only, while freezing showed no adverse effect on vitamin $\mathrm{C}$ and a good amount of vitamin $\mathrm{C}$ was retained even after the third cycle of BFC (Table 2). The total sugar content of juice increased during BFC (16.33 to $39.32 \%$ ) and TC (16.33 to $38.12 \mathrm{mg} \mathrm{ml}^{-1}$ ), no significant difference was observed in total sugar content of concentrates produced by either the technique.

\subsection{Effect of BFC and TC on the antioxidant property of juice}

Total phenolic content (TPC) of juice increased from 74.36 to $103.10 \mathrm{GAE} / 100 \mathrm{ml}$ during $1^{\text {st }}$ to $3^{\text {rd }}$ cycles of BFC, TC juice had $101.63 \mathrm{GAE} / 100 \mathrm{ml}$ of juice for the same degree of concentration (Table 2). Although no significant difference was observed in TPC, BFC retained the $\mathrm{DPPH}{ }^{\bullet}$ scavenging activity of the juice increased gradually from $1^{\text {st }}$ to $3^{\text {rd }}$ cycle, however, a reverse trend was observed when concentrated thermally (Table 2). The low temperature used for concentration had not changed the functional properties of phenolic components present in juice and so protected the DPPH ${ }^{\bullet}$ scavenging activity (MisHRA et al., 2014), while exposure of higher temperature for concentration unfavourably affected the structure of phenolic content and so reduced the $\mathrm{DPPH}^{\bullet}$ scavenging activity.

\subsection{Effect of BFC and TC on bitterness of juice}

The retention of naringin content was comparatively higher in juice concentrated by heating $\left(5.82 \mu \mathrm{g} \mathrm{ml}^{-1}\right.$ ) (Table 2). Being water-soluble in nature, the fraction of naringin was removed from the juice along with the removal of ice, while in the case of TC, naringin could not be eliminated from juice, and due to the concentration effect, the level of naringin increased in the juice. Naringin is a thermally stable component that may resist up to $100-120^{\circ} \mathrm{C}$ and above $120^{\circ} \mathrm{C}$ it follows first-order reaction (IOANNOU et al., 2018). 


\subsection{Colour analysis}

The unstable nature of anthocyanin is a main concern during the processing and treatment of pomelo juice (Fig. 4). $L$, hue, and a/b values of raw juice used for present investigation were $15.7,5.7$, and 9.3, respectively, and BFC had values 10.54, 3.72, and 15.47, respectively. Retention of anthocyanin content during BFC retains the redness (high $\mathrm{a} / \mathrm{b}$ value) of the juice. Anthocyanins being heat-sensitive are destroyed easily when heated and so significant increases in $L$ (48.42) and hue angle (24.78) were noticed. Destruction of anthocyanins and polymerisation of anthocyanins with other polyphenols are the key factors for the reduction of redness of juice during processing.

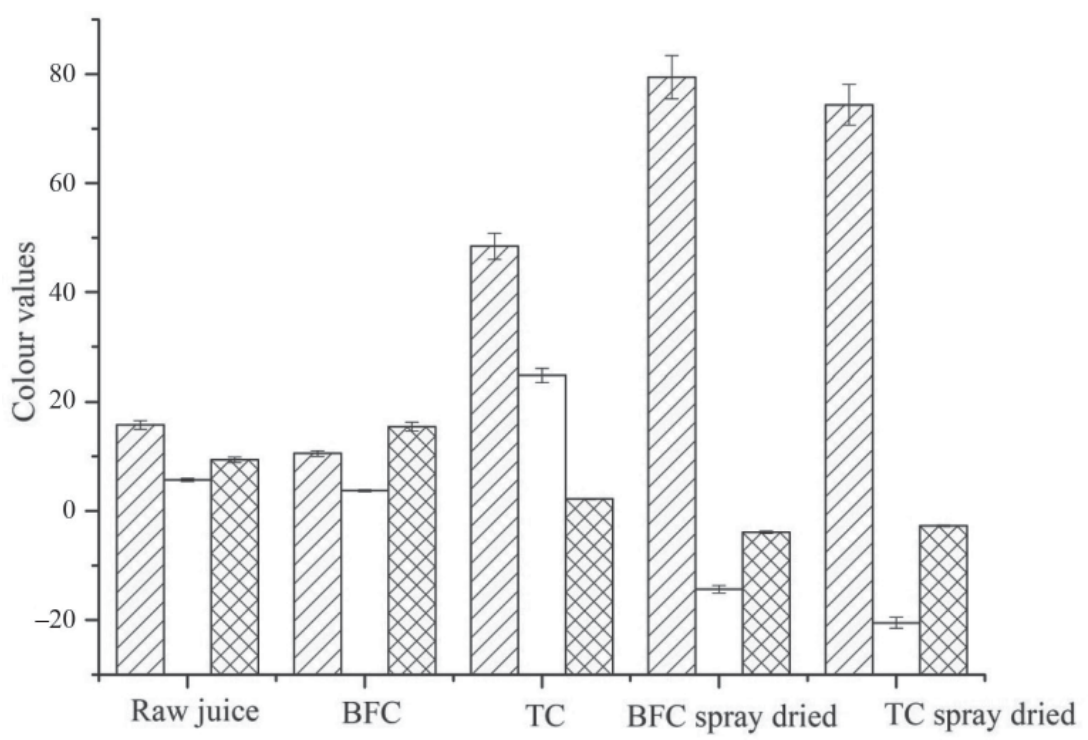

Fig. 4. Colour parameters of raw juice, BFC juice, TC juice, BFC spray dried powder, and TC spray dried powder $\mathbb{Z}: \mathrm{L} ; \square:$ hue; $\mathrm{X}: \mathrm{a} / \mathrm{b}$

\subsection{Comparative study of the effect of two different concentration techniques on physicochemical properties of spray dried powder}

Final moisture content of powder produced using a combination of freeze concentration and spray drying $(6.06 \%)$ was comparatively lower than of TC spray dried powder $(6.80 \%)$ (Table 3). Low temperature concentration protected the capillaries against damage and so facilitated the faster removal of moisture during spray drying. Damage to structure of capillaries during TC may be one of the feasible reasons of the reduced rate of removal of moisture in TC spray dried powder. 


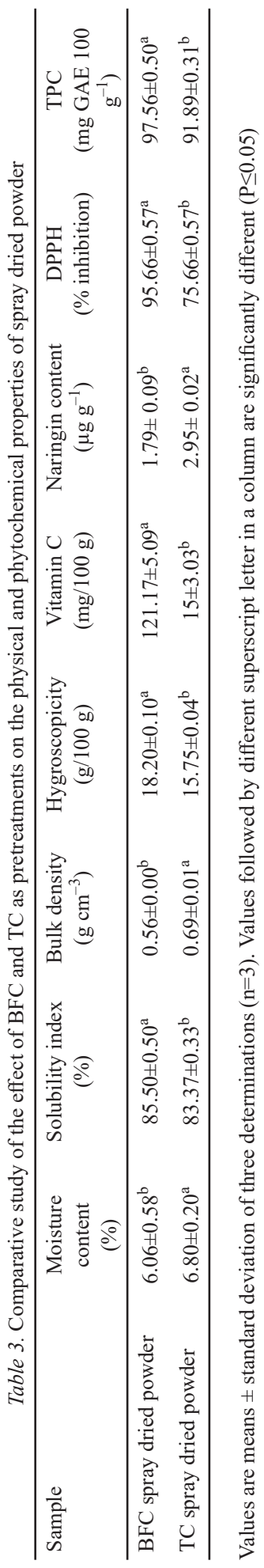


WSI of BFC powder and TC powder were $85.50 \%$ and $83.37 \%$, respectively. The powder produced from the concentrates showed good solubility, which indicated its application possibilities in new food product development. BD values of freeze- and the thermally concentrated powders were 0.56 and 0.69 , respectively (Table 3 ). Formation of ice crystals increases porosity of the cell wall, so by drying a porous and fluffy powder is obtained, however, denser powder particles were observed in the case of TC spray dried powder. Denser particles can easily settle into the interstitial spaces resulting high BD (Mishra et al., 2014). The increased porosity of the cell wall also increases the tendency of BFC spray dried powder to absorb moisture during storage (Table 3). Similar findings were observed by GouLA and ADAMOPOuLOs (2005) during spray drying of tomato pulp.

Vitamin $\mathrm{C}$ content of powder produced using a combination of BFC and spray drying was $121.17 \mathrm{mg} / 100 \mathrm{~g}$ (Table 3), while of TC spray dried was $15 \mathrm{mg} / 100 \mathrm{~g}$ only. Being unstable in nature, vitamin $\mathrm{C}$ degraded very easily during concentration by heat.

Naringin content of BFC spray dried powder was $1.79 \mu \mathrm{g} \mathrm{ml}^{-1}$, whereas of TC spray dried powder was $2.95 \mu \mathrm{g} \mathrm{g}^{-1}$ (Table 3).

$\mathrm{DPPH}^{\bullet}$ scavenging activity of BFC spray dried powder was significantly higher $(95.66 \%)$ than that of TC spray dried powder (Table 3). Decreased activity of DPPH ${ }^{\bullet}$ scavenging activity may be due to the breaking down of phenolic structure or synthesis of new different forms of phenolics with poor DPPH ${ }^{\bullet}$ scavenging activity (MisHRA et al., 2014). TPC values of BFC spray dried powder and TC spray dried powder were $97.56 \mathrm{mg} \mathrm{GAE} / 100 \mathrm{~g}$ and $91.89 \mathrm{mg} \mathrm{GAE} / 100 \mathrm{~g}$, respectively. Reduction in phenolic content may be attributed to high inlet temperature, which causes de-polymerisation and degradation of polyphenolic compounds.

Loss of redness in TC spray dried powder was due to the degradation and rapid oxidation of anthocyanins during concentration. BFC protected the anthocyanin content from oxidation and so BFC spray dried powder showed comparatively better retention of anthocyanins, which correlates with the lower hue angle and comparatively high a/b value (Fig. 4).

\section{Conclusions}

Concentration by BFC retained the phytochemical and colour properties of the pomelo fruit juice. Tuning to TC decreased colour values and physicochemical attributes. The powders produced by the two different pre-treatment techniques were significantly different on the basis of functional and physicochemical properties. Combination of BFC and spray drying provided a good quality powder with potent antioxidant properties, retention of anthocyanins, and better solubility index than of TC spray dried powder. Naringin content was significantly reduced in BFC concentrate and $\mathrm{BFC}$ spray dried powder, gaining increased acceptability among consumers. In conclusion, $\mathrm{BFC}$ as a pre-treatment permits the production of juice concentrate with higher retention of bioactive nutrients proving it a promising technique in the preservation of heat-labile constituents of juice.

\section{References}

Adnan, A., MushtaQ, M. \& Islam, T.UL. (2018): Fruit juice concentrates. -in: Rajauria, G. \& Tiwari, B.K. (Eds) Fruit juices: Extraction, composition, quality and analysis. Academic Press, London, pp. 217-240. 
AOAC (1990): Official methods of analysis of AOAC, Association of Official Analytical Chemists International, Washington, DC.

Bharali, R. \& Saikia, L. (2004): Physico-chemical changes associated with growth and development of pummelo (Rabab Tenga, white flesh, Citrus grandis L.) fruit. J. Food Sci. Tech., 41(6), 696-699.

Bohra, P. \& SRINIVAS, K.N. (2015): Development of nectar from pummelo (Citrus grandis), an underutilized fruit crop, by blending with kokum (Garcinia indica) and mango ginger (Curcuma amada). J. Andaman Sci. Assoc., 19(1), 70-74.

CAI, Y.Z. \& CORKE, H. (2000): Production and properties of spray-dried amaranthus betacyanin pigments. J. Food Sci., 65(7), 1248-1252.

Davis, W.B. (1947): Determination of flavanones in citrus fruits. Anal. Chem., 19(7), 476-478.

Fazaeli, M., Emam-Djomeh, Z., Ashtari, A.K. \& Omid, M. (2012): Effect of spray drying conditions and feed composition on the physical properties of black mulberry juice powder. Food Bioprod. Process., 90(4), 667675.

Goula, A.M. \& Adamopoulos, K.G. (2005): Spray drying of tomato pulp in dehumidified air: II. The effect on powder properties. J. Food Eng., 66(1), 35-42.

Ikegwu, O.J. \& EKwU, F.C. (2009): Thermal and physical properties of some tropical fruits of Nigeria. J. Food Technol., 7(2), 38-42.

Ioannou, I., M'hiri, N., ChaAban, H., Boudhrioua, N.M. \& Ghoul, M. (2018): Effect of the process, temperature, light and oxygen on naringin extraction and the evolution of its antioxidant activity. Int. J. Food Sci. Tech., 53(12), 2754-2760.

Mishra, P., Mishra, S. \& Mahanta, C.L. (2014): Effect of maltodextrin concentration and inlet temperature during spray drying on physicochemical and antioxidant properties of amla (Emblica officinalis) juice powder. Food Bioprod Process., 92(3), 252-258.

Murugesan, R. \& Orsat, V. (2011): Spray drying of elderberry (Sambucus nigra L.) juice to maintain its phenolic content. Dry. Technol., 29(14), 1729-1740.

Petzold, G., Moreno, J., Lastra, P., Rojas, K. \& Orellana, P. (2015): Block freeze concentration assisted by centrifugation applied to blueberry and pineapple juices. Innov. Food Sci. Emerg., 30, 192-197.

Semenov, G.V., Krasnova, I.S., Suvorov, O.A., Shuvalova, I.D. \& Posokhov, N.D. (2015): Influence of freezing and drying on phytochemical properties of various fruit. Biosci. Biotechnol. Res. Asia, 12(2), 1311-1320.

Subramanian, V., Hoseney, R.C. \& Bramel-Cox, P.J. (1994): Shear thinning properties of sorghum and corn starches. Cereal Chem., 71(3), 272-275. 